\title{
Bioethics: Using Its Historical and Social Context
}

\section{Citation}

Belkin, Gary S., and Allan M. Brandt. 2001. Bioethics: Using its historical and social context. International Anesthesiology Clinics 39(3): 1-11.

\section{Published Version}

http://journals.lww.com/anesthesiaclinics/pages/default.aspx

\section{Permanent link}

http://nrs.harvard.edu/urn-3:HUL.InstRepos:3415438

\section{Terms of Use}

This article was downloaded from Harvard University's DASH repository, and is made available under the terms and conditions applicable to Other Posted Material, as set forth at http:// nrs.harvard.edu/urn-3:HUL.InstRepos:dash.current.terms-of-use\#LAA

\section{Share Your Story}

The Harvard community has made this article openly available.

Please share how this access benefits you. Submit a story.

Accessibility 


\title{
Bioethics: Using Its Historical and Social Context
}

\author{
Gary S. Belkin, MD, PhD \\ Allan M. Brandt, PhD
}

On the one hand, bioethics seems an integral part of the landscape of medical practice. Ethics committees, clinical ethics journals, policies based on specific theories of informed consent and patient decision making are ubiquitous. However, on the other hand, questions arise, both within the bioethics literature and along corridors of hospitals and clinics, as to just how well bioethical theorizing reflects and meets the realities of clinical dilemmas and where it gets its authoritative voice. What does bioethical reasoning and writing know? What makes a particular ethical view count?

We hope to address these important questions by thinking historically about the development of bioethics. In the course of doing so we briefly describe some of the major "schools" and approaches that have emerged in the field. But more importantly, rather than pick or choose among them, we encourage thinking about how and why these ways of thinking about medicine emerged. We do so to cast bioethics as less a worked-out expertise than a historically contingent reflection of anxieties about medical practice that can change. The question should be less "what method is best to know the ethical?" than "what are our needs and ethical questions, and who should participate in addressing them?"

\section{- Bioethics Emerges}

The identified community of thinkers, writers, and practitioners that see themselves as studying or employing a unique kind of ethical expertise over medicine called "bioethics" began identifying itself as such in the late 1960 s and early 1970s. The first use of the term is usually attributed to Van Rensselear Potter and his 1970 article "Bioethics, science of survival." $1 \mathrm{His}$ use referred to a new science that would combine biology and human 
values to guide how we change the environment and our adaptation to it to wisely further civilization. This was quite different than its use soon thereafter, in 1971, to describe the creation of a new foundation, the Kennedy Center for Ethics at Georgetown University, where it referred to the application of moral analysis and critique to medical practice and biological technology.*

Historians have begun to consider how and why the perception, nature, and need for such a posture vis à vis medicine emerged at this time-that is, how do we explain the experience of medicine as a source of particular kinds of moral concerns, and the development of a particular kind of organized assessment, action, and expertise needed to deal with that? Asking that question of necessity invites another: how many legitimate ways are there to experience and respond to medicine as a realm of moral decision making? Is the bioethics of the Kennedy Center just one historical twist, or does it contain compelling concerns that deserve our attention over time and place?

The moral aspects of treating the sick have long been discussed both by those observing medicine and by those practicing it. But bioethicists have questioned the degree that any prior efforts are only superficially connected with the work of contemporary bioethics; they don't really count as medical ethics. Such is the usual reaction, for example, to the title (and content) of the classic work Medical Ethics by British physician Thomas Percival. Percival's ethics are not those of bioethics, the argument goes; they involve the ethics of doctors' conduct with each other and were intended to safeguard medical authority. Their orientation did not revolve around the status and claims of the patient. That characterization clouds much of how bioethicists tend to regard the actually quite common marriage of medical and moral thinking through time.

But by what yardstick do we measure something as legitimately engaging ethical questions? Irrespective of the similarity or difference between "medical ethics" now and then, in his context, Percival, an established writer and intellectual figure in his day, drew upon certain philosophers and controversies of the time, and his Medical Ethics may indeed reflect a rather liberal political project for its author. ${ }^{2}$ Does the value of a history of moral meanings in medicine depend upon its similarity with a current position, or is there something relevant and instructive in understanding how even undesirable ethical commitments get to be established and experienced as morally sophisticated and ethically demanding in their own times?

*While Sargent Shriver allegedly used the term privately also in 1970 in preliminary discussions over Kennedy family sponsorship of the Institute, its first public use was in published descriptions of the project. Sce Reich WT. The word 'biocthics': its birth and the legacy of those who shaped its meaning Kennedy Instutc of Ethics Journal 1995;5:319; Jonsen AR. The birth of biocthics. Oxford: Oxford University Press, 1998:27. For similar concerns about the ways the tcrm has hidden its historic specificity and possibly narrowness of focus and purpose, see Martenson R. The history of bioethics; an essay revicw. Bulletin of the History of Medicine and Allicel Sciences 2001;56:168-175. 
The answer to this question shapes the approach to ethical questions altogether. To what degree is an ethical iclea autonomous, arguable on its own terms, bearing information valuable and applicable on its face? To what degree is it instead a proxy for larger changes, more historically specific and contingent aspects of culture, without which its presumed logic and necessity would seem strange? Taking Percival, and the latter question, seriously would mean questioning the transcendent stability of the kinds of ethical commitments that irreconcilably conflict, at least on their own terms, with his. We will take such history seriously here, but not to undermine the possibility of a meaningful and prominent role for bioethics in medical practice. On the contrary, it is inclusion of an understanding of how historical circumstances shape the value and compelling nature of ethical formulations through time that can make bioethics more useful, and used.

\section{- Bioethics Unfolds. ... . and Unravels? From Principlism to Pluralism}

Bioethics offered a sharp critique of what was perceived as an insular world of medical research and a paternalistic tradition in medical practice. The reaction to a series of public revelations of abuses whereby human subjects were unknowingly coerced into participation in dangerous, nontherapeutic research encouraged the development of new institutions and procedurcs for scrutinizing human subjects research. These efforts, in the form of government investigations and the creation or expansion of oversight rules and regulations, used, and in turn nurtured, a new kind of asserted expertise in bioethics upon which to shape and justify such rapidly expanding scrutiny.

The Tuskegee Syphilis Study, the Willowbrook Hepatitis Study, and a long list of studies identified in anesthesiologist Henry Beecher's 1966 analysis in the New England Journal of Medicine ${ }^{3}$ epitomized the sense of a tragic failure of research medicine to respect basic human rights. Together these revelations, and others like them, exposed a research culture in which the interests of subjects could be fundamentally disregarded in the name of science. ${ }^{4}$ Rising concern about research ethics also pointed to more fundamental questions about the character of medical authority within clinical medicine. More formalized expectations of informed consent and peer and bioethicist scrutiny of research translated into similar calls for rules and oversight of clinical practice. ${ }^{5}$ Informed consent soon became the most basic premise for both research and clinical care. ${ }^{6}$

The reaction to abuses, the new expectations of clinical practice, and the rise of bioethics can also be fully understood only in the broader context of the rights-based movements for self-determination in the $1950 \mathrm{~s}$ and 1960s. These include the civil rights movement, the rise of a new 
women's rights movement, and early patients' rights activities focused principally on psychiatric issues of civil commitment and the right to refuse treatment. ${ }^{7-10}$ There can be little doubt that the rise of bioethics left a substantial mark on medical care. It has reoriented certain aspects of research and therapeutic practice. It led to a new patient-centered ethic, often advocating patients as genuine participants in their care rather than only the objects of diagnosis and treatment.

The emergence of a unique bioethics expertise needs to be seen within yet another, related context. Many of its leading figures in the late 1960 s and early 1970 s came from, and were responding to, perceived limitations of more theologically based approaches to ethics. At this time many of the ethical issues receiving heated debate involved issues of biology - contraception, abortion, population control, and genetics, issues tightly related to notions of sinfulness and that required reconsideration of the role of religious authority. Interest in creating a more secular and diverse political and ethical culture to take on these new biotechnological questions encouraged approaches to moral philosophy that could offer a solid ground of justification to replace religious faith within the bounds of its own reasoned logic and method. For example, Daniel Callahan, who founded the first bioethics think tank, the Hastings Center, and Robert Veatch, its first employee, who would later lead the Kennedy Center for Ethics, both had theological interests and backgrounds. Callahan served as executive editor of the Catholic periodical Commonweal prior to his creation of Hastings, and Veatch's studies took him to the Harvard Divinity School. Both explicitly questioned the continued value and relevance of theological moral traditions and searched for a more objective methodology that would also be an improvement over more skeptical and situational moral philosophies. $f^{11,12}$

Other leading figures such as Albert Jonsen, Hans Jonas, Paul Ramsey, Joseph Fletcher, and others came from theological backgrounds and interests. Fletcher and Ramsey did not "secularize" their work as much as the others. Because of this, their failure to have as enduring an influence on the field can further illustrate the degree that bioethics was a "working through" of changes within the field of moral philosophy and its distancing from theological sources. Ramsey, for example, was briefly celebrated for taking on the authority of medical practice, but he did so through a clear theological commitment to the inviolability of the body. That com-

+Veatch specifically ticd his work to efforts within academic moral philosophy by philosophers such as Roderick Firth, William Frankena, and John Rawls, who challenged a trend that saw normative debates Rodetick about cthics as litte more than assertions of preference. veate pos analysis of the moral good that could be impersonal and objectively describe the principle and rules for moral behaviors in ways that could compel assent. Sec Jonsen AR. Birth of biochics. New York: Oxford University Press, 1998:56-57 and Belkin GS. (PhD Diss.) Death before dying: mind, body, ethics, and the Harvard brain death committee, 1955-1970. Ann Arbor; UMI, 2000:253-263. 
mitment also limited the degree of autonomy patients had and thus limited the degree Ramsey would influence the field. ${ }^{13}$ Fletcher celebrated and wished to further liberate autonomous choice but also did so through a theological commitment, in his case to a version of Christian love. That resulted in a position referred to as situation ethics, whereby the ethical could be known only in the moment by analyzing the loving commitments at stake in particular circumstances. ${ }^{14}$ His approach, too, would be initially rejected in lieu of the more primary search at the time for a more basic, presumably objective, set of secular ethical practices and commitments that focused on sketching and exploring the structure of autonomous choice.

Given these origins, perspectives, and problems, it is not surprising that the initial focus of bioethics was to define and defend a principle of the autonomy of the patient and his or her decisions and uniqueness that demanded respect that was more secular, objective, and rights-based. A summary principle was a category of moral action easily captured in a thumbnail title, easily recognizable and communicated, there to challenge medical authority and its more diffuse justifications. Indeed, "principlism" was the term applied to such a still-dominant ethical framework. Here was a small set of presumably basic commitments that when met addressed ethical problems. It emerged as the primary form of bioethical analysis and discourse because it clearly captured the social and political shift at the time in privileging an understanding of individual authority. At the same time it afforded a combination of apparent objectivity as a measure, a sought-aftcr "metric" to lend to moral choices an authoritative, verifiable replicability. ${ }^{15}$ It provided stable ground and scientific credibility to take on science. Principlism included, in addition to autonomy, the principles of beneficence, nonmalfeasance, and justice. But autonomy reigned, and the other principles often took on their significance to the degree they protected individuals.

But to some, principlism was too much of a thumbnail sketch and too vague about how this restricted list of principles was to be ordered in particular circumstances. What determined which principle was more important? If the ethical problem was, precisely, the fact that a patient's wish and a physician's notion of benefit or nonmalfeasance clashed, what determined that autonomy did, or should, trump? The problem with principlism was thus the absence of a larger moral theory, a broader explanation and theoretical justification to guide us in meeting the reality of moral dilemmas that did not lend themselves to a short menu of commitments but needed to be more basic and to encompass a description of how to reason morally to engage such dilemmas. ${ }^{16}$ This same attention to the slippery diversity of moral problem solving revived attention to a tradition called casuistry, a method of moral deliberation that addressed this problem by rejecting what seemed to be top-down principles and moral theories. Casuistry did so by arguing that we do not form our moral positions 
by applying theory or principles but by drawing comparisons between the diverse experiences and dilemmas in our moral lives and by searching for that set of circumstances closest to the one for which there is disagreement, but for which there is nonetheless moral consensus. Our moral intuitions are to be trusted, not derived. They can be a jumping-off point with which to tease apart the salient features that lend to one set of details a consensus, so as to define more carefully what makes its nearly similar pair controversial, and thus ideally resolve the underlying disagreement. ${ }^{17}$

Care ethics and narrative ethics both further capitalize on the importance of detail and circumstance. In care ethics, the specific personal histories and kinds of relationships between individuals drive moral obligations; without knowledge of these things, such obligations cannot be known or derived. Narrative ethics similarly emphasizes how the unfolding logic of the resolution to a particular ethical situation lies in how it hangs together as a coherent and powerful narrative. ${ }^{18-19}$ Expanding skepticism within bioethics as to whether the field has achieved any reliable method of ethical inquiry leads to calls for a notion of bioethics as primarily a good facilitator. ${ }^{20-21}$ Here, the bioethicist provides the skills and analysis that assist people to describe their underlying moral commitments in a way that might foster, not the clear identification of what is ethical, but at least, and at best, a working consensus for action. ${ }^{22}$

Casuistry, care ethics, narrative ethics, and other variations question the principlist and moral theory approaches. Their appearance reflects, however, a seemingly timeless tension between rules and circumstance, between an attempt at moral deliberation that derives ethics from larger theory, rules, or basic principles, or one that builds moral conclusions or consensus through responding to the particular circumstances or moral intuitions that appear in the context of a given case. Understanding and testing ethical positions in historical contexts does not necessarily favor the circumstantial side of this tension. History may look for features of a given time and place that shape our beliefs, but it doesn't rule out the possibility of shared commitments and the real possibility of forming enduring traditions and moral theories over time. Indeed, history can enable us to better understand how commitments with a larger permanence and persistent sense of necessity and "rightness" maintain those qualities with real effect over our conduct and beliefs. It can also be a tool to study how, and not merely assume that, a more contingent, context-driven approach to bioethics may seem to work. It can help us think about why only a certain narrative, a specified relationship, or a particular moral consensus seems compelling. Rather than unravel or merely facilitate, bioethics after principlism can continue to generate knowledge about ethical choices in medicine by incorporating more reflective social science practices.

Our interest is not only to pay attention to the historical circumstances that may favor the success of one approach to bioethics over another but also to listen for the histories and historical assumptions that make a 
particular view compelling. For example, historian Tod Chambers ${ }^{23}$ has described how seminal writers in bioethics rely on certain understandings of history within which their moral visions can be coherent. Leading proponents of principlism, casuistry, justice theory, and other approaches each have discernibly different assumptions about the historical conditions of the modern world that have created one or another possibility for relating and understanding each other. These assumptions structure and make coherent such ethical "schools."

\section{Historical Ethics}

Our approach is therefore to consider the value of the historical context of ethical positions to bioethics. ${ }^{24}$ A more self-consciously "historical ethics" in medicine can supplement the way we talk about and use ethics and help bridge the gap between asserted expertise in conferences, and skepticism and confusion in hallways. Take, for example, the typical Bioethics 101 case of an 87-year-old man unconscious and unresponsive on a respirator with antibiotic-resistant pneumonia, terminal, end-stage cancer, and no expressed wishes around treatment. We would countenance as ethical removal of respirator support upon consent of the family. This is ostensibly because we are merely extending that patient's right to selfdetermination and to choose to refuse medical interventions through a reliable proxy. But consensus on such a case is possible not solely because the notion of autonomous/proxy refusal per se is so conceptually well developed. That consensus also rests upon a shared sense in this historical moment of confidence in certain medical prognostication, acceptance of certain limits to perceived suffering, expectations about familial roles, etc. That these contingent aspects of our cultural experience are operative is clearer if some of the details of the case change. Suppose this patient left a living will indicating he wanted everything done? How to respond if his daughter urged withdrawal nonetheless, citing her sense of his suffering in the last few months of the eight years she has devoted to caring for him at home? What relevance is there if the insurance company argues that the patient is being inappropriately hospitalized or if the supply of the hospital's ventilators is being strained? What if there is disagreement as to whether the therapy will work? What if he is conscious and suffering and asks for extra morphine to ensure pain relief but also to hasten death?

Each of these scenarios accents a different ethical commitment-to ideas about the ethical significance of relationships, distributive justice, beneficence, and autonomy, respectively. But they do not exclude each other, and choosing which approach has authority for the "right" answer can often seem arbitrary. While a historical approach towards bioethics will not magically solve such a situation, it can improve the process in various ways. 
For one thing, it can encourage and model asking questions about the process of moral deliberation itself rather than focus on the result of finding a right answer. Each of the variations on the case needs to be explained as to why it causes uncertainty or moral discomfort. If we better understand the historical reasons that patient agency became more central, or notions of "futility" established or meaningful, we can put in context how to understand feared deviations from it. The power of bioethical formulations is in their resonance with experience, in their consistency with how attitudes toward suffering, expectations about medicine, customs of establishing desert and entitlement, get formed, cohere, and change. Those things need to be studied more explicitly and directly.

History can shift our attention to how experiences and practice are established in culture rather than focus on abstracted terms, concepts, and formulations. We can consider various notions of personhood and agency when deliberating about cloning, but we had also better consider how people have advocated, rejected, reshaped, and incorporated all sorts of seemingly unusual technological interventions to enhance reproductive success through the centuries. Euthanasia can be advocated within a framework of liberty claims over one's own body, but we need to examine as well why and how interest in such an autonomous power has fluctuated significantly throughout history. Why such an interest now; why especially one suffused by a fear of alienation and pain? The connection between the moral standing and authority of physicians with their identity as decisive interveners into the working of the body has long fluctuated through time. An attempt at a theory to pick and choose the limits of such an identity needs also to include asking why and how those expectations change through history.

Asking such questions also underscores the need to ask more empiric questions about the present. Such assessment would require considerable anthropological and sociological investigation of a range of variables that are under any circumstances quite difficult to measure. Do patients today really exercise more autonomy over medical decision making? Are research subjects better protected from the intensive and competitive demands of new scientific knowledge? Just as we might assess equity in access to medical care, we might ask if all patients have had equal access to the advantages of new ethical precepts. Is there a socioeconomic gradient? Do better-educated patients, for example, benefit more significantly from informed consent than less well-educated ones?

A historical perspective also simply brings more voices to the table. If bioethics can be more explicitly engaged in thinking about how and why its problems and formulations occur and change the way they do, a larger conversation is possible. There could be a conversation that sees greater relevance of other scholarly disciplines (sociology, anthropology, history) and of the diversity of personal visions and concerns and past experience. 


\section{- Do New Circumstances Mean New Ethics?}

In short, bioethics is historically contingent; it reflected-and responded to-a series of specific contemporary critiques of biomedical practice and was fundamentally shaped by the social and political conventions of the time in which it emerged. Therefore, the bioethics that emerged in this period may no longer be a particularly good "fit" for the range of moral and ethical dilemmas currently confronting American medicine. Informed consent, the hallmark of bioethics, takes physicians' authority as a given. The prevailing assumption was that if physicians adequately respected patients' autonomy, their considerable authority would pass (through knowledge) back to their patients. Patient autonomy, therefore, rested upon an a priori physician autonomy. Bioethics in this form rarely considered the broader social and institutional contexts in which this ethical transaction occurred.

Compared with the 1960s and 1970s, we now come full circle and find that an increasing source of ethical concern is how the authority and autonomy of the provider are under attack. If patient autonomy was at the center of discussion over the past decades, today physician autonomy seems to be the critical issue. As opposed to a story of discerning the choice and autonomous action of an individual overwhelmed by the consequences of modern technology, new paradigmatic cases seem to compel attention:

A patient with moderate back pain of relatively short duration comes to see her primary care physician. After taking a history and carefully examining the patient, the physician recommends ibuprofen and rest. He explains that if there is no improvement in the next week the patient should let him know so that they can follow up. As the patient is leaving, she asks if she might need an MRI. He explains that it currently isn't indicated, but that if she doesn't improve-as he expects she will-they can pursue other diagnostic options, perhaps including an MRI. The patient then asks if he is not ordering the MRI now because of financial incentives. The doctor is troubled by this exchange and what it represents about his relationship with his patient.

This vignette indicates that forces external to the doctor-patient interaction have altered the character of the relationship. Even though the doctor may believe that he would never compromise a patient's appropriate care regardless of financial incentives, his patient is concerned. The quality of trust has been altered, perhaps permanently. The patient worries that the doctor has lost his authority to care, and that his autonomous capacity to act in the patient's interest is eroded by new and often hidden rules and financial incentives. Such issues are, of course, not new to managed care. Physicians have always operated under the influence of considerable external (and sometimes hidden) incentives. The point here is that bioethics - as it came to be constituted in the 1970s and 1980soffered little in the way of analyzing such forces, be they economic, cultural, or psychological. Nonetheless, managed care has challenged the authority upon which bioethics was constituted. 
As bioethics evolved over recent decades, the central question for health care providers confronted with an ethical dilemma was typically "what should I do?" Today, many of the dilemmas of medical care focus instead on the question "what can I do?" This question recognizes essential constraints on clinical and moral choices. This change reflects an important historical shift in assumptions about our health care system and aspects of agency within it and suggests that we may need to rethink medical ethics in critical new ways.

Although the parameters of a new bioethics are far from clear, several broad questions are already apparent. ${ }^{25} \mathrm{~A}$ historical ethics calls for understanding not only how changing needs open us to changing ethical approaches, but also how they forms attention on understanding actual practice. We will need more empiric research on practices associated with ethics, both in patient-provider relationships and in our health care institutions and systems. Medical ethics is moving beyond the assertion of critical principles to assess concretely the obstacles that may inhibit our ability to realize them. This agenda requires a wide range of disciplines, from clinical caregivers to the humanities and social sciences, as well as stronger assessment of the relationship of health policy to medical ethics. Only a complex dialogue that helps to reveal consensual social and moral values in a diverse culture-a dialogue among experts and the many constituencies doing medical work and seeking medical care-is likely to result in a new and effective medical ethics. In this respect it seems likely that as medicine changes, so too must our medical ethics. $\ddagger$

\section{References}

1. Potter VR. Bioethics, science of survival. Perspectives on Biology and Medicine 1970; $14: 127-53$

2. Belkin GS. History and bioethics: the uses of Thomas Percival. Medical Humanities Review Fall 1998;1 $\div 39-59$

3. Beecher HK. Ethics and clinical research. New Engl J Med 1966;274;1354-1360

4. Jonsen AR. The birth of bioethics. New York: Oxford University Press, 1998

5. Rothman DJ. Strangers at the bedsicle. New York: Basic Books, 1991

6. Faden RR, Beauchamp TL. A history and theory of informed consent. New York: Oxford University Press, 1986

7. Kluger R. Simple justice: the history of Brown v. Board of Education and black America. New York: Knopf, 1975

8. Echols A. Daring to be bad: radical feminism in America-1967-1975. Minneapolis: University of Minnesota Press, 1989

9. Appelbaum PS. Almost a revolution: mental health law and the limits of change. New York: Oxford University Press, 1994

tConcluding paragraphs appear in slightly modified from Brandt AM. Biocthics then and now. Lahey Clinic Medical Ethics Newsletter, Spring 2000:1-2. 
10. Filene PG. In the arms of others: a culcural history of the right-to-die in America. Chicago: IR Dee, 1998

11. Callahan D. Abortion: law, choice and morality. New York: The Macmillan Co, 1970

12. Veatch RM. Value freedom in science and technology. Missoula: Scholars Press, 1976

13. Ramsey P. The patient as person. New Haven: Yale University, 1970

14. Fletcher J. Situation ethics-the new morality. Philadelphia: The Westminster Press, 1966

15. Evans JH. A sociological account of the growth of principlism. Hastings Center Report 2000;30:31-38

16. Gert B, Culver CM, Clouser KD. Bioethics: a return to the fundamentals. New York: Oxford University Press, 1997

17. Jonsen A, Toulmin S. The abuse of casuistry. Berkeley: University of California Press, 1988

18. Veatch RM. The place of care in ethical theory. Journal of Medicine and Philosophy $1988 ; 23: 210-224$

19. Hawkins A. Literature, philosophy and medical ethics: let the dialogue go on. Journal of Medicine and Ploilosophy 1996;21:341-354

20. Casanett DJ, Daskal F, Lantos J. The authority of the clinical ethicist. Hastings Center Report Nov-Dec 1998;28:6-11

21. Yoder $S$. The nature of ethical expertise. Hastings Center Report Nov-Dec 1998;28:1119

22. Moreno JD. Deciding together: bioethics and moral consensus. New York: Oxford University Press, 1995

23. Chambers $T$. Retrodiction and the histories of bioethics. Medical Humanities Review Spring 1998;12(1):9-22

24. Belkin G. Toward a historical ethics. Cambridge Quarterly of Healthcare Ethics 2001; $10: 345-350$

25. Kleinman A, Renee $\mathrm{C}$, Fox RC, Brandt AM, eds. Bioethics and beyond. Daedelus 1999;128(4). 